\title{
Alterações em propriedades do solo adubado com composto orgânico e efeito na qualidade das sementes de alface
}

\author{
Antonio Ismael Inácio Cardoso ${ }^{1 *}$; Kauê P Ferreira ${ }^{2}$; Ronaldo Matheus Vieira Júnior ${ }^{1}$; Cristiane Alcarde ${ }^{1}$ \\ ${ }^{1}$ UNESP-FCA, C. Postal 237, 18603-970 Botucatu-SP; ismaeldh@fca.unesp.br; ronaldo.vieira@rocketmail.com; cristiane_alcarde@ \\ hotmail.com; ${ }^{2}$ Korin Agropecuária Ltda, Ipeúna-SP; kpferreira@gmail.com; *autor correspondente
}

\section{RESUMO}

Este trabalho teve por objetivo avaliar o efeito de doses de composto orgânico nas propriedades do solo, no teor de nutrientes e qualidade das sementes de alface. O delineamento experimental utilizado foi blocos ao acaso, com cinco tratamentos (T0: sem composto orgânico; T30: $30 \mathrm{t} \mathrm{ha}^{-1}$; T60: $60 \mathrm{t} \mathrm{ha}^{-1}$; T90: $90 \mathrm{t} \mathrm{ha}^{-1}$ e T120: 120 t ha $^{-1}$ de composto orgânico) e cinco repetições. Não houve efeito significativo de doses de composto orgânico para os teores de todos os macronutrientes nas sementes, assim como na qualidade fisiológica (germinação e vigor). Observou-se aumentos lineares nos teores de matéria orgânica, cálcio, magnésio, soma de bases, CTC e saturação por bases do solo ao final do ciclo da cultura.

Palavras-chave: Lactuca sativa L., adubação orgânica, fertilidade do solo, teor de nutrientes.

\section{ABSTRACT}

Changes in soil properties managed with organic compost and its effect on lettuce seed quality

This work had the objective to evaluate the effect of organic compost levels in chemical properties of soil, nutrient contents of seeds and quality of lettuce seeds. The experimental design was randomized blocks, with five treatments (T0: without organic compost; T30: $30 \mathrm{t} \mathrm{ha}^{-1}$; T60: $60 \mathrm{t} \mathrm{ha}^{-1}$; T90: $90 \mathrm{t} \mathrm{ha}^{-1}$ and T120: $120 \mathrm{t} \mathrm{ha}^{-1}$ of organic compost) and five replications. There were not differences in seed nutrient contents and physiological quality (germination and vigor). However, linear increases were observed in organic matter levels, calcium, magnesium, basis sum, CEC and base saturation of soil at final culture cycle.

Keywords: Lactuca sativa L., organic fertilization, soil fertility, nutrient content.

(Recebido para publicação em 9 de dezembro de 2010; aceito em 30 de setembro de 2011) (Received on December 9, 2010; accepted on September 30, 2011)

\begin{abstract}
A s hortaliças se diferenciam quanto às exigências nutricionais e no padrão de absorção de nutrientes durante seu crescimento e desenvolvimento, sendo que aquelas não frutíferas, como a alface, apresentam lenta absorção de nutrientes durante a primeira metade do ciclo de cultivo, que acelera-se próximo à colheita. Para alface, quando se busca a produção de sementes, ocorre aumento no seu ciclo e a extração de nutrientes deve ser maior que no cultivo para o consumo de folhas, pois, segundo Carvalho \& Nakagawa (2000), no início da fase reprodutiva a exigência nutricional para a maioria das espécies torna-se mais intensa, sendo mais crítica por ocasião da formação das sementes, quando considerável quantidade de nutrientes é translocada.
\end{abstract}

Carvalho (1978) verificou que a adubação nitrogenada não afetou a produção nem a qualidade de sementes de alface. $\mathrm{O}$ autor atribuiu essa resposta à produção possivelmente devido ao fato de o experimento ter sido conduzido em solo de alta fertilidade. Kano (2006) e
Kano et al. (2006) estudaram diferentes doses de fósforo no plantio e de potássio em cobertura, respectivamente, na produção de sementes de alface crespa 'Verônica' e obtiveram aumento linear na produção com o aumento das doses sem afetar a qualidade das sementes.

Existem pesquisas em que se estuda o efeito de adubos químicos na produção de sementes de alface, porém, não foram encontrados trabalhos com adubação orgânica, nem estudos em que se tenham avaliado os teores de nutrientes nas sementes. A adubação orgânica tem grande importância no cultivo de hortaliças, principalmente em solos de clima tropical, onde a decomposição da matéria orgânica ocorre mais intensamente. A matéria orgânica melhora as condições químicas, físicas e biológicas do solo, o que reforça o interesse em sua utilização como fonte de nutrientes para a cultura da alface (Vidigal et al., 1997). A liberação dos nutrientes dos adubos orgânicos é mais lenta que a dos adubos minerais solúveis, pois é dependente da mineralização da matéria orgânica, porém apresenta maior duração, pela liberação ao longo do ciclo da planta (Marchesini et al., 1988).

Para o cultivo de alface visando a produção de folhas, vários autores (Santos et al., 2001; Villas Bôas et al., 2004; Yuri et al., 2004; Lopes et al., 2005) relataram aumento na produção quando se utiliza adubação orgânica. Porém, nestes trabalhos com alface, raramente são relatados os efeitos desta adubação orgânica nas propriedades químicas do solo.

Pela escassez de informações sobre o efeito da adubação orgânica nas sementes e no solo, o objetivo deste trabalho foi avaliar a influência de doses de composto orgânico nas características químicas do solo e das sementes, assim como na qualidade fisiológica destas.

\section{MATERIAL E MÉTODOS}

Este trabalho foi desenvolvido na Fazenda Experimental São Manuel, localizada no município de São Manuel- 
-SP, pertencente à Faculdade de Ciências Agronômicas (FCA) da Universidade Estadual Paulista (UNESP), Campus de Botucatu $\left(22^{\circ} 44^{\prime} \mathrm{S}, 48^{\circ} 34^{\prime} \mathrm{W}\right.$, altitude média $750 \mathrm{~m}$ ). As plantas foram conduzidas em estruturas de cultivo protegido não climatizadas, tipo arco, com $20 \mathrm{~m}$ de comprimento, largura de $7 \mathrm{~m}$ e pé-direito de 2,5 m, sendo que os arcos, na sua parte mais alta, atingem altura de 3,8 m.

O solo utilizado no experimento foi um Latossolo Vermelho Distrófico Típico com os seguintes resultados obtidos na análise química: $\mathrm{pH}\left(\mathrm{CaCl}_{2}\right)=4,0$; $\mathrm{P}_{\text {resina }}=2 \mathrm{mg} \mathrm{dm}^{-3}$; matéria orgânica $=7$ $\mathrm{g} \mathrm{dm}^{-3} ; \mathrm{V} \%=11$; e os valores de $\mathrm{H}+\mathrm{Al}$; $\mathrm{K}$; $\mathrm{Ca}$; $\mathrm{Mg}$; $\mathrm{SB}$ e CTC, expressos em $\mathrm{mmol}_{\mathrm{c}} \mathrm{dm}^{-3}$, respectivamente de: 25; 1,$2 ; 2,0 ; 1,0 ; 3,0$ e 28. A análise física desse solo indicou 761, 199 e $40 \mathrm{~g} \mathrm{~kg}^{-1}$ de areia, argila e silte, respectivamente.

Pelo fato de o ciclo da alface para a produção de sementes ser maior do que para o cultivo comercial e a maior demanda por nutrientes quando o objetivo são as sementes (Kano, 2006; Kano et al., 2006), utilizou-se quantidades de composto orgânico acima da recomendação sugerida por Raij et al. (1996) (30 $\mathrm{t} \mathrm{ha}^{-1}$ ) para o cultivo comercial, resultando, assim, nos seguintes tratamentos: T0: tratamento sem composto orgânico; T30: $30 \mathrm{t} \mathrm{ha}^{-1}$; T60: $60 \mathrm{t} \mathrm{ha}^{-1}$; T90: $90 \mathrm{t}$ $\mathrm{ha}^{-1}$ e T120: $120 \mathrm{t} \mathrm{ha}^{-1}$ de composto orgânico. Estas doses corresponderam a 0, 225, 450, 675 e $900 \mathrm{~g}$ /vaso de composto. Foi utilizado o composto comercial Biomix ${ }^{\circledR}$, produto à base de cama de frango e farelo de soja, que apresentou a seguinte composição química: $\mathrm{pH}=$ 7,7 e os valores de $\mathrm{MO} ; \mathrm{N} ; \mathrm{P}_{2} \mathrm{O}_{5} ; \mathrm{K}_{2} \mathrm{O}$; $\mathrm{Ca} ; \mathrm{Mg}$ e de $\mathrm{S}$, expressos em $\%$, respectivamente de: $53 ; 1,30 ; 0,90 ; 0,47 ; 6,80$; 0,25 e 0,34 . A relação $\mathrm{C} / \mathrm{N}$ foi de $23 / 1$ e a umidade do composto de $60 \%$. As doses foram em função do peso fresco.

O delineamento experimental utilizado foi blocos ao acaso, com cinco tratamentos (doses de composto orgânico) e cinco repetições, com sete plantas por parcela conduzidas até o fim do ciclo para a obtenção das sementes, sendo avaliadas três plantas úteis por parcela.

A calagem foi realizada 30 dias antes do transplante das mudas, utilizando-se calcário de alta reatividade (PRNT=
$90 \%$ ), de modo a elevar a saturação por bases a $80 \%$, conforme a recomendação sugerida por Raij et al. (1996).

A adubação de plantio foi feita com a adição de composto orgânico, de acordo com os tratamentos, além da adição de $600 \mathrm{~kg} \mathrm{ha}^{-1}$ de $\mathrm{P}_{2} \mathrm{O}_{5}$, conforme recomendação de Kano (2006) para produção de sementes de alface, utilizando-se o superfosfato triplo (10 g/vaso). Não foram utilizados outros adubos no plantio ou em cobertura. Decidiu-se realizar a adubação com fósforo, pois, em experimento anterior neste mesmo solo com alface, as plantas não se desenvolviam em função da ausência deste nutriente, mesmo com elevadas doses de composto orgânico.

Foi utilizada a alface crespa cultivar Verônica, sendo as mudas transplantadas em 21 de maio de 2007, para vasos de plástico com volume de $15 \mathrm{~L}$ onde foram conduzidas colocando-se uma planta por vaso. O espaçamento foi de 1,0 m entre linhas de vasos e estes foram distribuídos na área de modo a proporcionar o espaçamento de $0,5 \mathrm{~m}$ entre plantas (centro a centro dos vasos). As plantas foram tutoradas de modo a evitar o tombamento das mesmas na fase reprodutiva e a irrigação foi realizada por meio de gotejadores instalados individualmente em cada vaso. Em média, foram feitas duas ou três irrigações por semana, com cerca de $600 \mathrm{~mL}$ de água por planta em cada irrigação.

Após o preparo do solo e transplante das mudas, foi realizada análise química em amostras de solo de cada parcela para se obter as informações dos teores dos nutrientes atingidos, assim como ao final do ciclo da cultura ( 12 de dezembro de 2007), coletando-se o solo de três vasos por parcela. As amostras foram encaminhadas para o Laboratório de Fertilidade do Solo do Depto. de Recursos Naturais, para a determinação dos teores de potássio, fósforo, cálcio e magnésio, além do $\mathrm{pH}$, teor de matéria orgânica, soma de bases (SB), capacidade de troca catiônica (CTC) e saturação por bases $(\mathrm{V} \%)$. As amostras foram secas em estufa e analisadas conforme metodologia preconizada por Raij \& Quagio (1983).

A colheita das sementes foi realizada em uma única vez em cada planta, cortando-se as plantas quando aproximadamente $50 \%$ das sementes estavam maduras (Viggiano, 1990). Após a colheita, foi feita a limpeza das sementes com a utilização de peneiras e separador por densidade (modelo De Leo I) para retirada dos restos de cultura e sementes chochas. Também foram coletadas todas as folhas das plantas úteis ao final do ciclo para obtenção dos teores dos nutrientes.

Para a obtenção dos teores dos macronutrientes (nitrogênio, fósforo, potássio, cálcio, magnésio e enxofre) foram utilizadas amostras de sementes e de folhas das três plantas, que foram levadas ao laboratório e devidamente lavadas. Após a remoção do excesso de água utilizada na lavagem, as amostras foram colocadas em saco de papel, identificadas e levadas para secagem em estufa de circulação forçada de ar a $65^{\circ} \mathrm{C}$, até atingirem massa constante. Em seguida, cada amostra passou pela moagem em moinho tipo Willey e as determinações dos macronutrientes foram feitas conforme metodologias apresentadas por Malavolta et al. (1997), sendo obtidos os teores de nitrogênio, fósforo, potássio, cálcio, magnésio e enxofre em $\mathrm{g} \mathrm{kg}^{-1}$ de sementes ou de folhas.

Também foram realizadas as seguintes avaliações em relação à qualidade das sementes: massa de mil sementes e qualidade fisiológica (germinação e vigor). Utilizou-se balança digital com precisão de $0,001 \mathrm{~g}$ para obter a massa de 1000 sementes de cada parcela. O teste padrão de germinação foi realizado conforme as Regras para Análise de Sementes (Brasil, 1992), com utilização de caixa gerbox em germinador a $20^{\circ} \mathrm{C}$ e 100 sementes por parcela. Para a primeira contagem foram consideradas as plântulas normais contabilizadas e retiradas aos quatro dias. A contagem final foi realizada aos sete dias, sendo consideradas germinadas as plântulas com o aparecimento das folhas cotiledonares.

As médias por parcela, sem transformação de dados, foram submetidas à análise de variância e, no caso de $\mathrm{F}$ significativo para tratamentos (doses de composto), foi realizada análise de regressão. Foi utilizado o programa de análises estatísticas Estat.

\section{RESULTADOS E DISCUSSÃO}

Com o aumento das doses de com- 


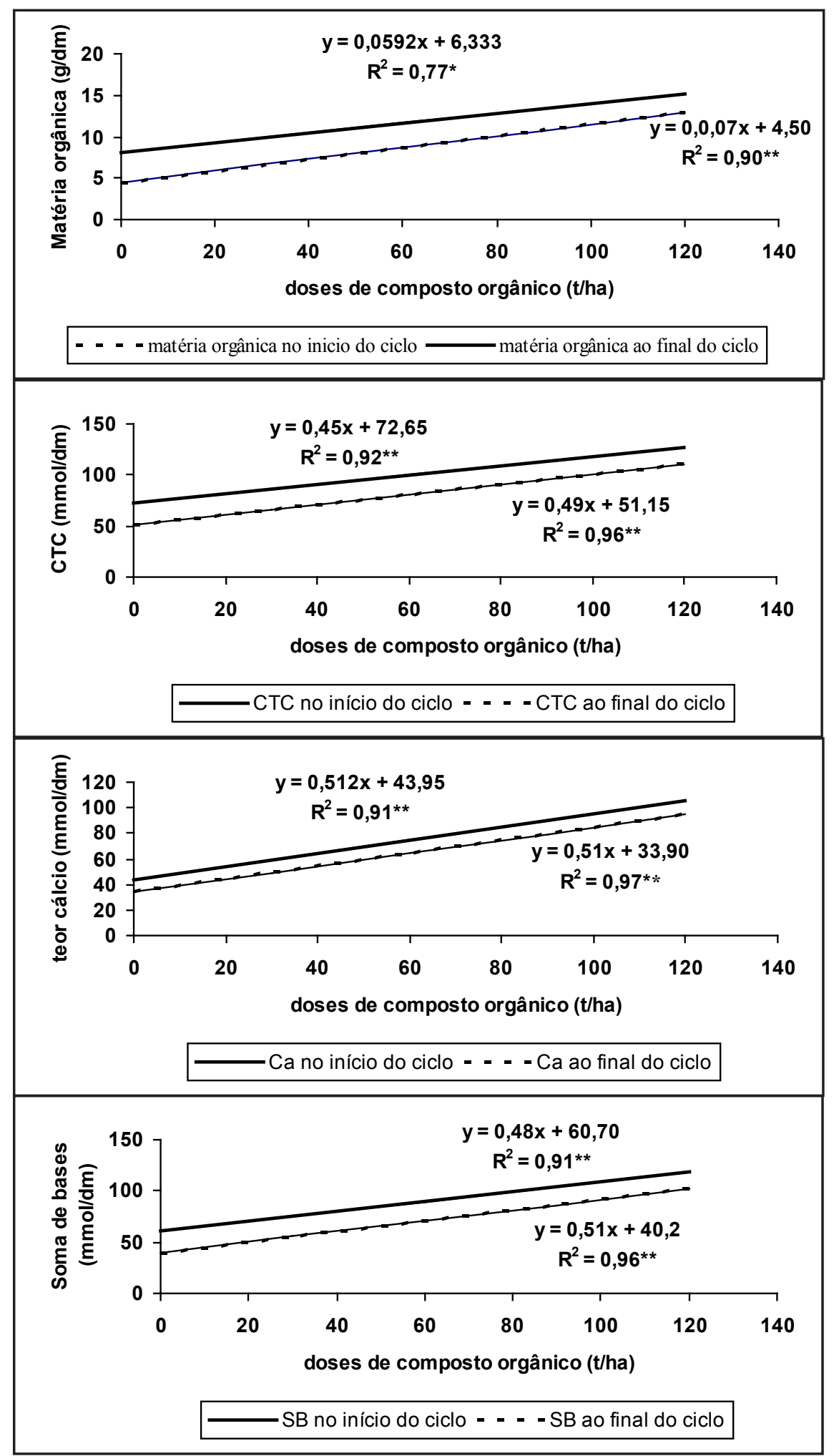

Figura 1. Matéria orgânica, capacidade de troca catiônica (CTC), teor de cálcio e soma de bases (SB) no solo após aplicação das diferentes quantidades de composto orgânico (início do ciclo) e ao final do ciclo (organic matter, cation exchange capacity (CTC), calcium content and basis sum (SB) in soil after application of different organic compost levels (cycle beginning) and at the end of cycle). São Manuel, UNESP, 2007.

posto observou-se aumento linear na matéria orgânica do solo (Figura 1). Pela regressão, estima-se que para cada
$10 \mathrm{t} \mathrm{ha}^{-1}$ de composto adicionado ao solo, obtém-se aumento de $0,7 \mathrm{~g} \mathrm{dm}^{-3}$ no teor de matéria orgânica no solo no início do ciclo. Também Damatto Júnior et al. (2006) relataram aumento linear no teor de matéria orgânica do solo com doses de composto orgânico na cultura da bananeira. Este aumento no teor de matéria orgânica do solo proporcionou aumento na CTC da ordem de $4,5 \mathrm{mmol}_{\text {c }}$ $\mathrm{dm}^{-3}$ para cada 10 tha $^{-1}$ de composto adicionado ao solo. Também foram obtidos aumentos na soma de bases (Figura 1). Santos et al. (2001) também relataram aumentos na CTC e soma de bases do solo com quantidades crescentes de composto orgânico na cultura da alface. Porém, estes autores, assim como Damatto Júnior et al. (2006), observaram aumentos nos teores de fósforo o que não foi observado neste trabalho, provavelmente pela grande quantidade de $\mathrm{P}_{2} \mathrm{O}_{5}\left(600 \mathrm{~kg} \mathrm{ha}^{-1}\right)$ aplicados junto com o composto em todos os tratamentos, além do composto utilizado neste trabalho ser pobre em fósforo.

Dos macronutrientes, apenas o cálcio apresentou aumento no teor no início do ciclo com as quantidades crescentes de composto orgânico, provavelmente por ser este o nutriente com maior teor $(6,8 \%)$ no composto orgânico. Não foram observadas diferenças entre os tratamentos nos teores de $\mathrm{P}, \mathrm{K}, \mathrm{Mg}$ e saturação por bases (V\%), com média de $198 \mathrm{mg} \mathrm{dm}^{-3} ; 9,3 \mathrm{mmol}_{\mathrm{c}} \mathrm{dm}^{-3} ; 5,7 \mathrm{mmol}_{\mathrm{c}}$ $\mathrm{dm}^{-3}$ e $89 \%$, respectivamente. Também Damatto Júnior et al. (2006) não obtiveram aumento no teor de $\mathrm{K}$ no solo com aplicação de composto orgânico.

Assim como no início do ciclo, ao final do ciclo observou-se aumento linear na matéria orgânica do solo com o aumento nas doses de composto (Figura 1). Pela regressão, estima-se que para cada $10 \mathrm{t} \mathrm{ha}^{-1}$ de composto adicionado ao solo, obtém-se aumento de $0,6 \mathrm{~g} \mathrm{dm}^{-3}$ no teor de matéria orgânica no solo ao final do ciclo. Este aumento no teor de matéria orgânica do solo proporcionou aumento na CTC da ordem de $4,9 \mathrm{mmol}_{\mathrm{c}}$ $\mathrm{dm}^{-3}$ para cada 10 tha $^{-1}$ de composto adicionado ao solo. Também foram obtidos aumentos nos teores de cálcio e da soma de bases (Figura 1).

Diferindo do observado inicialmente, além do cálcio, também o magnésio apresentou aumento no teor com as quantidades crescentes de composto orgânico ao final do ciclo (Figura 2). 


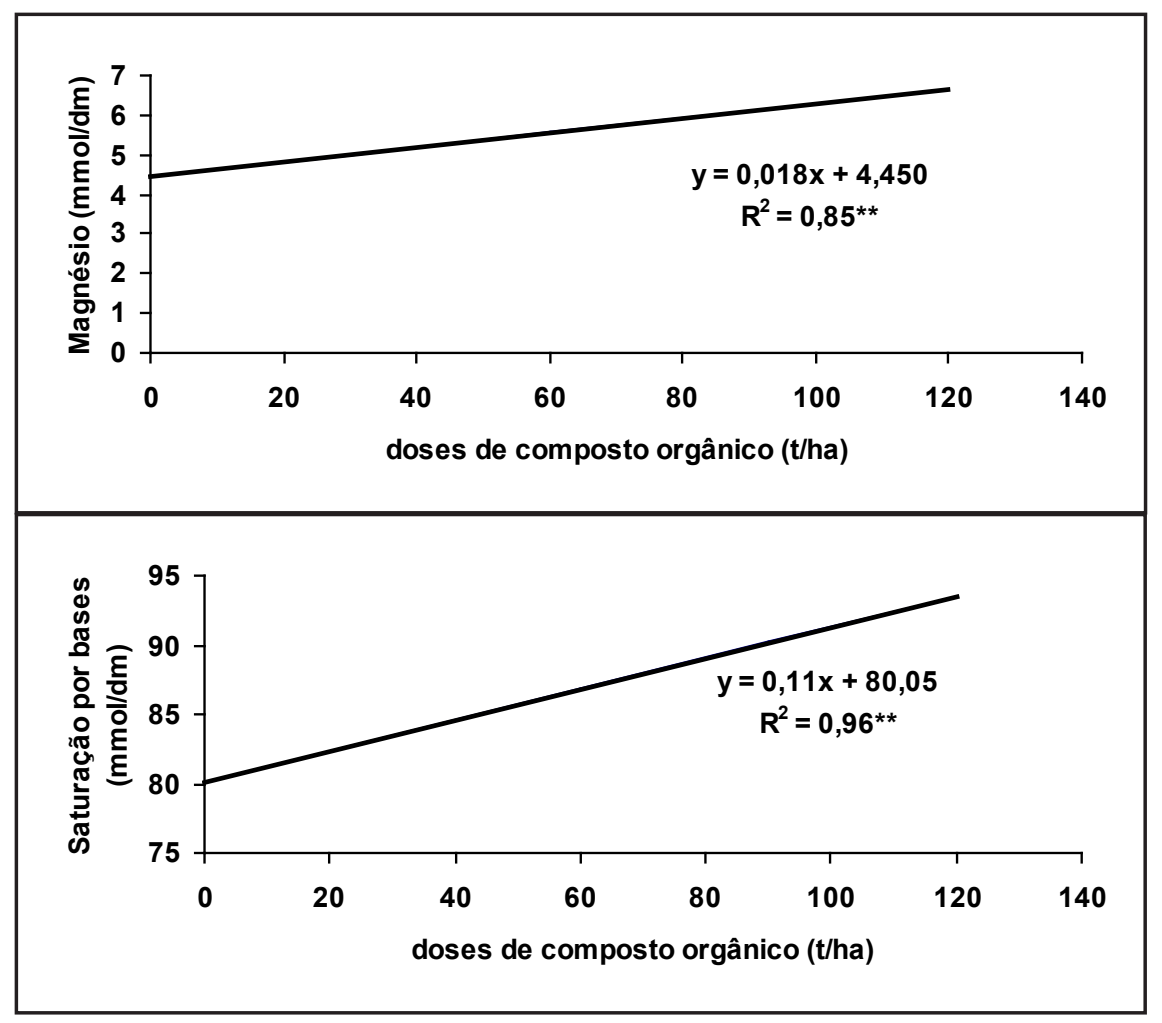

Figura 2. Teores de magnésio e saturação por bases do solo no final do ciclo nas diferentes quantidades de composto orgânico (magnesium content and base saturation of soil at the end of the cycle in different organic compost levels). São Manuel, UNESP, 2007.

Não foram observadas diferenças entre os tratamentos nos teores de K, diferindo de Magro (2009) que, trabalhando com doses de composto orgânico na produção de sementes de brócolos, relatou aumento linear no teor deste nutriente no solo. Também a saturação por bases $(\mathrm{V} \%)$ apresentou elevação nos valores com as quantidades crescentes de composto orgânico (Figura 2), provavelmente pelos aumentos nos teores de cálcio e magnésio no solo, além da possível adsorção de hidrogênio e alumínio na superfície da matéria orgânica, conforme relatado por Damatto Júnior et al. (2006). Segundo Hoyt \& Turner (1975), a adição de matéria orgânica ao solo pode ter efeito semelhante ao da calagem em termos de correção da acidez.

Para a maioria dos nutrientes, os teores obtidos no solo foram altos em todos os tratamentos $\left(198 \mathrm{mg} \mathrm{dm}^{-3} \mathrm{de}\right.$ P; 9,3 e 5,7 $\mathrm{mmol}_{\mathrm{c}} \mathrm{dm}^{-3}$ de $\mathrm{K}$ e $\mathrm{Mg}$, respectivamente), o que favoreceu um bom desenvolvimento das plantas, mesmo sem realizar adubações em cobertura e somente com fósforo no plantio.

Não houve efeito significativo de doses de composto orgânico para os rica em proteínas, além de ser um nutriente facilmente redistribuído na planta (Malavolta et al., 1997).

Nas folhas não foi observada variação significativa para todos os nutrientes avaliados, com média de $14 ; 1,8 ; 40 ; 36$; 6,1 e $2,1 \mathrm{~g} \mathrm{~kg}^{-1}$ de matéria seca para $\mathrm{N}$, $\mathrm{P}, \mathrm{K}, \mathrm{Ca}, \mathrm{Mg}$ e S, respectivamente. Diferentemente das sementes, os nutrientes com maiores teores foram o potássio e o cálcio. Também Damatto Júnior et al. (2006) relataram que, mesmo com alterações observadas em algumas características químicas do solo, a adubação orgânica não promoveu diferença nas concentrações de nutrientes nas folhas das bananeiras. Já Souza et al. (2005) obtiveram aumento nos teores de $\mathrm{P}, \mathrm{K}$ e $\mathrm{Mg}$ nas folhas de alface com aumento nas doses de composto orgânico. Porém, estes autores avaliaram plantas em pleno desenvolvimento vegetativo, enquanto que neste trabalho as plantas já estavam senescentes, após intensa translocação de nutrientes para as sementes.

Ao se comparar os teores nas sementes e nas folhas, percebe-se que o teor de nitrogênio na semente $\left(44 \mathrm{~g} \mathrm{~kg}^{-1}\right)$ é cerca de três vezes superior àquele presente na folha $\left(14 \mathrm{~g} \mathrm{~kg}^{-1}\right)$. Isso pode ser explicado pela mobilidade desse nutriente na planta. Do mesmo modo, pode-se observar a redistribuição do fósforo da parte vegetativa $\left(1,8 \mathrm{~g} \mathrm{~kg}^{-1}\right)$ para as sementes $\left(10 \mathrm{~g} \mathrm{~kg}^{-1}\right)$, onde apresentou teor cerca de seis vezes a mais. Estes resultados também foram observados por Kano (2006) nesta mesma cultivar de alface quando avaliou doses de fósforo. Também Carvalho (1978) obteve teor elevado de fósforo nas sementes de alface $\left(6,4 \mathrm{~g} \mathrm{~kg}^{-1}\right)$. O maior teor de fósforo na semente pode ser justificado pelo fato deste nutriente ser armazenado como sais do ácido fítico, constituindo a fitina (Lott et al., 1995).

Para o cálcio, o teor encontrado na semente $\left(3 \mathrm{~g} \mathrm{~kg}^{-1}\right)$ foi cerca de doze vezes menor que o obtido na folha (36 $\mathrm{g} \mathrm{kg}^{-1}$ ), provavelmente devido sua baixa mobilidade pelo floema (Malavolta et al., 1997).

Beninni (2002), ao avaliar a concentração de macronutrientes em alface cultivar Verônica, verificou que, no ponto de colheita, a parte aérea das plantas cultivadas no sistema convencional 
apresentou concentração de: 38,24; 5,74; 78,33; 12,23; 3,11 e 3,87 $\mathrm{g} \mathrm{kg}^{-1}$ respectivamente de $\mathrm{N}, \mathrm{P}, \mathrm{K}, \mathrm{Ca}, \mathrm{Mg}$ e $\mathrm{S}$, demonstrando que a ordem decrescente dos teores dos macronutrientes encontrados foi: potássio $>$ nitrogênio $>$ cálcio $>$ fósforo $>$ magnésio $>$ enxofre. Já Raij et al. (1996) relataram a seguinte ordem decrescente de nutrientes nas folhas: potássio $>$ nitrogênio $>$ cálcio $>$ fósforo $\approx$ magnésio $>$ enxofre. Neste trabalho, a ordem nos teores nas folhas foi um pouco diferente: potássio $\approx$ cálcio $>$ nitrogênio $>$ magnésio $>$ enxofre $>$ fósforo. Porém, neste trabalho as plantas foram avaliadas ao final do ciclo para produção de sementes, quando já havia ocorrido a translocação de nutrientes móveis das folhas para as sementes.

Quanto à qualidade das sementes, não houve efeito significativo de doses de composto orgânico para todas as características avaliadas: massa de mil sementes, primeira contagem $(98,8 \%)$ e germinação final (99\%), demonstrando que as doses aplicadas de composto orgânico não influenciaram a qualidade das sementes.

Para a massa de mil sementes, obteve-se média de $0,93 \mathrm{~g}$, valor próximo ao relatado por outros autores em alface (Carvalho, 1978; Reghin et al., 2000; Kano, 2006; Kano et al., 2006).

Kano et al. (2006) também não observaram diferença na qualidade das sementes ao estudarem doses crescentes de $\mathrm{K}_{2} \mathrm{O}$ nesta mesma cultivar avaliada. Soffer \& Smith (1974), que avaliaram plantas de alface cultivadas em cinco níveis de fertilidade do solo, também não verificaram efeito na qualidade das sementes. Kano (2006) estudou diferentes doses de $\mathrm{P}_{2} \mathrm{O}_{5}$ e também não verificou efeito na qualidade das sementes desta mesma cultivar de alface. Também Magro et al. (2010) não observaram diferença na qualidade (germinação e vigor) de sementes de brócolos produzidas com diferentes doses ( 0 a $120 \mathrm{t} \mathrm{ha}^{-1}$ ) do mesmo composto orgânico utilizado neste trabalho, apesar de ter sido em um solo com menor teor de matéria orgânica $\left(4 \mathrm{~g} \mathrm{dm}^{-3}\right)$. Portanto, os resultados obtidos nesse experimento são concordantes com o de Delouche (1980), que ressalta a capacidade das plantas em ajustar a produção e qualidade das sementes mesmo em condições adversas (neste caso, baixo teor de matéria orgânica no solo). Sob o ponto de vista evolucionário, esse fato tem um alto valor para a sobrevivência.

Ressalta-se que neste trabalho usou-se sementes beneficiadas, pois as sementes chochas foram eliminadas durante o beneficiamento para retirada das impurezas com peneiras e por diferença de densidade, obtendo-se as sementes que seriam comercializadas, o que justifica a boa germinação e vigor. Quanto aos trabalhos citados nem sempre há descrição na metodologia sobre o uso ou não de sementes beneficiadas, o que dificulta a comparação. Apenas no trabalho de Magro et al. (2010) os autores relataram que os testes foram realizados com as sementes de brócolos beneficiadas e, neste trabalho, também não verificaram diferença na germinação das sementes com as doses de composto orgânico.

Conclui-se que, para as condições deste experimento, as quantidades de composto orgânico avaliadas não influenciaram a qualidade das sementes de alface, assim como os teores de macronutrientes nestas, porém elevaram os teores de matéria orgânica, $\mathrm{Ca}, \mathrm{Mg}$, $\mathrm{SB}, \mathrm{CTC}$ e V\% do solo ao final do ciclo.

\section{AGRADECIMENTOS}

Ao CNPq pelas bolsas concedidas e à FAPESP pelo auxílio financeiro (processo 06/57527-7).

\section{REFERÊNCIAS}

BENINNI ERY. 2002. Concentração e acúmulo de macronutrientes em alface cultivada em sistemas hidropônicos e convencional. Londrina: UEL. 33p. (Dissertação mestrado).

BRASIL. Ministério da Agricultura e Reforma Agrária. 1992. Regras para análise de sementes. Brasília: SNDA/DNDV/CLAV. $365 \mathrm{p}$.

CARVALHO JL. 1978. Efeito da adubação nitrogenada sobre a produção e qualidade de sementes de alface (Lactuca sativa L.). Piracicaba: USP ESALQ. 54p. (Dissertação mestrado).

CARVALHO NM; NAKAGAWA J. 2000. Sementes: ciência, tecnologia e produção. 4. ed. Jaboticabal: FUNEP. 588p.

DAMATTO JÚNIOR ER; VILLAS BÔAS
RL; LEONEL S; FERNANDES DM. 2006. Alterações em propriedades de solo adubado com doses de composto orgânico sob cultivo de bananeira. Revista Brasileira de Fruticultura 28: 546-549.

DELOUCHE JC. 1980. Environmental effects on seed development and seed quality. HortScience 15: 775-780.

HOYT PB; TURNER RC. 1975. Effect of organic materials added to very acid soils on $\mathrm{pH}$, aluminum, exchangeable $\mathrm{NH} 4$ and crop yields. Soil Science 119: 227-237.

KANO C. 2006. Doses de fósforo no acúmulo de nutrientes, na produção e na qualidade de sementes de alface. Botucatu: UNESP FCA. 112p. (Tese doutorado).

KANO C; CARDOSO AII; HIGUTI ARO; VILLAS BÔAS RL. 2006. Doses de potássio na produção e qualidade de sementes de alface. Horticultura Brasileira 24: 356-359.

KANO C; CARDOSO AII; VILLAS-BOAS RL. 2010. Influência de doses de potássio nos teores de macronutrientes em plantas e sementes de alface. Horticultura Brasileira 28: 287-291

LOPES JC; RIBEIRO LG; ARAÚJO MG; BERALDO MRBS. 2005. Produção de alface com doses de lodo de esgoto. Horticultura Brasileira 23: 143-147.

LOTT JNA; GREENWOOD JS; BATTEN GD. 1995. Mechanisms and regulation of mineral nutrient storage during seed development. In: KIGEL J; GALILI G (eds). Seed development and germination. New York: Marcel Dekker. p.215-235.

MAGRO FO. 2009. Doses de composto orgânico na produção e qualidade de sementes de brócolis. Botucatu: UNESP FCA. 50p. (Dissertação mestrado).

MAGRO FO; ARRUDA N; CASA J; SALATA AC; CARDOSO AII; FERNANDES DM. 2010. Composto orgânico na produção e qualidade de sementes de brócolis. Ciência e Agrotecnologia 34: 596-602.

MALAVOLTA E; VITTI GC; OLIVEIRA AS. 1997. Avaliação do estado nutricional das plantas: princípios e aplicações. 2. ed. Piracicaba: POTAFÓS. 319p.

MARCHESINI A; ALLIEVI L; COMOTTI E; FERARI A. 1988. Long-term effects of quality compost treatment on soil. Plant and Soil 106: 253-261.

RAIJ B; CANTARELLA H; QUAGGIO JA; FURLANI AMC. 1996. Recomendações de adubação e calagem para o Estado de São Paulo. 2. ed. Campinas: Instituto Agronômico \& Fundação IAC. 285p.

RAIJ B; QUAGGIO JA. 1983. Métodos de análises de solo para fins de fertilidade. Campinas: Instituto Agronômico. 31p. (Boletim Técnico, 81).

REGHIN MY; OTTO RF; ROCHA A. 2000. Indução do florescimento e produção de sementes de alface com diferentes doses de ácido giberélico. Horticultura Brasileira 18: 171-175.

SANTOS RHS; SILVA F; CASALI VWD; CONDE AR. 2001. Efeito residual da adubação com composto orgânico sobre o crescimento 
e produção de alface. Pesquisa Agropecuária Brasileira 36: 1395-1398.

SOFFER H; SMITH OE. 1974. Studies on lettuce seed quality: V. nutritional effects. Journal of American Society for Horticultural Science 99: 459-463.

SOUZA PA; NEGREIROS MZ; MENEZES JB; BEZERRA NETO F; SOUZA GLFM; CARNEIRO CR; QUEIROGA CF. 2005. Características químicas de folhas de alface cultivada sob efeito residual da adubação com composto orgânico. Horticultura Brasileira 23: 754-757.

VIDIGAL SM; SEDIYAMA MAN; GARCIA NCP; MATOS AT. 1997. Produção de alface cultivada com diferentes compostos orgânicos e dejetos suínos. Horticultura Brasileira 15: 35-39.

VIGGIANO J. 1990. Produção de sementes de alface. In: CASTELLANE PD; NICOLOSI WM; HASEGAWA M. Produção de sementes de hortaliças. Jaboticabal: FUNEP. p.1-13.
VILLAS BÔAS RL; PASSOS JC; FERNANDES DM; BÜLL LT; CEZAR VR; GOTO R. 2004. Efeito de doses e tipos de compostos orgânicos na produção de alface em dois solos sob ambiente protegido. Horticultura Brasileira 22: $28-34$.

YURI JE; RESENDE GM; RODRIGUES JR; MOTA JH; SOUZA RJ. 2004. Efeito de composto orgânico sobre a produção e características comerciais de alface americana. Horticultura Brasileira, Brasília 22: 127-130. 